\title{
Maintenance of Functional Capacity and Hemodynamic Responses After Discharge from Cardiac Rehabilitation
}

\author{
José Andrés Trejos-Montoya ${ }^{1}$, Braulio Alonso Sánchez-Ureña ${ }^{1}$, Peter Walter Grandjean ${ }^{2}$, \\ Luis Alberto Blanco-Romero ${ }^{1}$, Jorge Enrique Salas-Cabrera ${ }^{1}$, Vera Rodríguez-Cambronero, \\ Felipe Araya-Ramírez ${ }^{1}$
}

${ }^{1}$ Department of Human Movement Science and Quality of Life, National University, Heredia, Costa Rica

${ }^{2}$ Department of Health, Human Performance and Recreation, Baylor University, Waco, USA

\section{Email address:}

jtrejos@una.cr(J. A. Trejos-Montoya)

\section{To cite this article:}

José Andrés Trejos-Montoya, Braulio Alonso Sánchez-Ureña, Peter Walter Grandjean, Luis Alberto Blanco-Romero, Jorge Enrique SalasCabrera, Vera Rodríguez-Cambronero, Felipe Araya-Ramírez. Maintenance of Functional Capacity and Hemodynamic Responses After Discharge from Cardiac Rehabilitation. American Journal of Sports Science. Vol. 6, No. 3, 2018, pp. 108-113.

doi: 10.11648/j.ajss.20180603.16

Received: May 7, 2018; Accepted: June 7, 2018; Published: June 29, 2018

\begin{abstract}
Purpose: To examine the maintenance of functional capacity and hemodynamic responses to exercise in cardiac patients two and a half years after discharge from cardiac rehabilitation program. Methods: Eighty-eight patients with CVD were contacted after discharge from our university-based phase II cardiac rehabilitation program between 2011 and 2014. Only fifty-two patients agreed to participate in the study (age $=59.1 \pm 14$ years, height $=1.67 \pm 0.9 \mathrm{~m}$, weight $=77.5 \pm 13.2 \mathrm{~kg}$, BMI $=27.6 \pm 3.6 \mathrm{~kg} / \mathrm{m}^{2}$ ). Patients returned $30.7 \pm 9.0$ months after CR discharge and performed a 6 -minute walking test (6MWT). Functional capacity was measured by the distance walked during the 6MWT and hemodynamic responses were measured after the test. Multiple repeated-measures ANOVAs were used to compare variables at baseline (Pre), end of CR (Post1) and follow-up 2.5 yrs after completing CR (Post2). Bonferroni post hoc analysis was used when appropriate. Significance was accepted at the $p<0.05$ level. Results: Functional capacity improved $23.1 \%$ with CR $(443 \pm 95 \mathrm{~m}$ Pre to 545 $\pm 87 \mathrm{~m}$ Post $1, p<0.001)$ and was maintained at follow-up $(545 \pm 87 \mathrm{~m}$ Post 1 to $542 \pm 71 \mathrm{~m}$ Post2, $p>0.05)$. Resting heart rate decreased $7.0 \%$ between CR and follow-up $(71 \pm 9.0 \mathrm{bpm}$ Post1 to $66 \pm 11 \mathrm{bpm}$ Post2, $p=0.007)$. DBP decreased by $5.6 \%$ after CR $(71 \pm 10 \mathrm{mmHg}$ Pre to $67 \pm 9.0 \mathrm{mmHg}$ Post1, $p=0.002)$ and was maintained after discharge $(67 \pm 9.0 \mathrm{mmHg}$ Post1 to $66 \pm 9.0 \mathrm{mmHg}$ Post $2, p>0.05)$. Patients experienced a greater five-minute heart rate recovery $(24 \pm 13 \mathrm{bpm}$ Pre vs $38 \pm 16$ bpm Post1, $p<0.001$ ), which was maintained at follow-up ( $38 \pm 16 \mathrm{bpm}$ Post1 vs $39 \pm 12 \mathrm{bpm}$ Post2, $p>0.05$ ). Greater SBP recovery was also found $(20 \pm 12 \mathrm{mmHg}$ Pre vs $29 \pm 16 \mathrm{mmHg}$ Post1, $p=0.004)$ and maintained at follow-up $(29 \pm 16 \mathrm{mmHg}$ Post1 vs $27 \pm 11 \mathrm{mmHg}$ Post2, $p>0.05)$. RPP was greater $(13066 \pm 3152 \mathrm{mmHg} * b p m$ Pre vs $15934 \pm 3962 \mathrm{mmHg} * b p m$ Post $1, p<0.001)$ and maintained at follow-up Post1 vs $14933 \pm 3505 \mathrm{mmHg} * \mathrm{bpm}$ Post $2, p=0.288)$. Conclusion: Patients maintained their functional capacity and hemodynamic responses to exercise two and a half years after discharge from CR, despite they gained body weight.
\end{abstract}

Keywords: Cardiac Rehabilitation, Functional Capacity, Hemodynamic Responses

\section{Introduction}

Cardiovascular disease (CVD) is one of the leading causes of death in Costa Rica and worldwide $[1,2]$. The death rate attributable to CVD in the United States was 30.8\% in 2013; one in three deaths were due to CVD and one in seven deaths were related to coronary artery disease (CAD) [3]. Currently,
CVD is one of the main public health problems in the United States, due to the high medical costs of treatment such as hospital services, prescribed medications, physicians and other health care professionals [3].

In Costa Rica, approximately $25 \%$ of all deaths in 2012 were due to CVD, and among them, CAD was the most prevalent (16.2\%). Furthermore, myocardial infarction (MI) 
accounted for $38.5 \%$ of all CAD deaths [1]. Coronary risk factors such as hypertension, high cholesterol, smoking, obesity, diabetes and physical inactivity increase the risk of CVD [3]. In Costa Rica, it has been reported that approximately 5,500 discharges from hospitals of the Costa Rican Social Security Administration System are for CAD and 1,886 discharges are for MI [1].

A traditional 12-wk cardiac Rehabilitation (CR) for patients with CVD have positive effects on body composition, lipid profile, coronary risk factors, functional capacity, maximal oxygen consumption $\left(\mathrm{VO}_{2} \mathrm{max}\right)$, muscular strength, improvement in quality of life and reduction of cardiac mortality [4-15]. In addition, improvements in hemodynamic responses to exercise in patients with CVD and after coronary artery bypass surgery have been reported $[5,16]$.

Despite the multiple benefits gained by CVD patients after a traditional 12-wk CR program, benefits in functional capacity, $\mathrm{VO}_{2} \mathrm{max}$, physical activity levels, coronary risk factors, or muscle strength decreased or were not maintained over 3, 12 and 18 months [17-21]. Conversely, patients who followed weekly exercise recommendations maintained their benefits for a year or more after completing a CR program [6, 22-25]. During follow-up, Hansen et al. [17], reported no changes observed for body weight and body mass index after 18 months. A couple of studies reported that total physical activity was not different between groups at 12 or 18 months $[6,21]$. However, others reported that physical activity was lower after 6 o 12 months of follow-up after CR program [18]. However, there is still limited information regarding the maintenance of functional capacity and hemodynamic responses to exercise after patients are discharged from a CR program $[6,22,23,26]$. Therefore, the purpose of this study was to examine the maintenance of functional capacity and hemodynamic responses to exercise in cardiac patients two to three years after discharge from a traditional 12-wk CR program.

\section{Methods}

\subsection{Study Overview}

A retrospective and follow-up study where 88 patients $(65$ men and 23 women) with CVD were contacted after discharge from a university-based phase II cardiac rehabilitation program from 2011 to 2014. Only Fifty-two patients agreed to participate in the study (39 men and 13 women), age $=59 \pm 14$ years, height $=1.67 \pm 0.9 \mathrm{~m}$, weight $=77.5 \pm 13.0 \mathrm{~kg}$, BMI $=27.6 \pm 3.6 \mathrm{~kg} / \mathrm{m}^{2}$ and waist circumference $=96 \pm 10 \mathrm{~cm}$. Cardiac conditions of the patients were coronary artery disease $(73.1 \%)$, valve replacement (11.6\%), arrhythmia $(7.7 \%)$, myocardiopathy $(3.8 \%)$ and other conditions (1.9\%). The study was conducted according to the principles of the Declaration of Helsinki, Fortaleza, 2013. Participation in this study was voluntary, and the experimental procedures, risks and benefits were explained to each patient. Patients signed an informed consent before starting the exercise testing.

Patients completed pre-and post-CR evaluations and then returned $30.7 \pm 9.0$ months after discharge and performed a six-minute walk test (6MWT). All physiological variables were measured at baseline (Pre), the end of CR (Post1) and return visit after $\mathrm{CR}$ discharge (Post2). Body weight (BW), body mass index (BMI), waist circumference (WC) were recorded and resting heart rate (HR), systolic blood pressure (SBP), and diastolic blood pressure (DBP) were measured before and five-minutes after the 6MWT using a standardized protocol. The same technicians measured all physiological variables of interest. First, patients were asked to remain comfortably seated for five minutes prior to measurements of heart rate and blood pressure, without crossing their legs, back supported and left arm at heart level. SBP and DBP were measured using a sphygmomanometer (Welch Allyn, MI, FL 33172 USA) with appropriate cuff size for each patient. Then, BW was measured using a (Tanita BC554 Ironman, Arlington Heights, IL 60005 USA) where the patient wearing minimal clothing and shoes removed. WC were obtained using a waist tape measure where patients were on standing position, arms at the sides, feet together and abdomen relaxed. The measurement of WC was taken horizontal above the umbilicus and below the xiphoid process.

\subsection{CR Exercise Protocol}

All exercise sessions were performed in a traditional 12-wk CR program and were monitored with ECG telemetry (Quinton Q-Tel RMS, Cardiac Science, Bothell, WA 98021 USA) and supervised by a general physician and an exercise specialist. The exercise duration was prescribed for 20 to 45 minutes per session (increments of 5 minutes per week until a total of 45 minutes), 3 times per week at $40 \%$ to $80 \%$ of $\mathrm{VO}_{2}$ reserve using a treadmill (Quinton Medtrack CR-60, Cardiac Science, Bothell, WA 98021 USA) and cycle ergometer (Monark 828E, Monark Exercise AB, Vansbro, Sweden). Exercise intensity was also monitored based on heart rate reserve, Borg Scale (11-13) or resting heart rate $(+20$ or +30 beats per minute) in patients taking beta-blockers.

\subsection{MWT and Hemodynamic Response Measurements}

Patients performed the 6MWT according to a standardized protocol described previously [27]. A resting HR, SBP, DBP and an electrocardiographic (ECG) rhythm strip were obtained prior to each test at baseline (Pre), the end of CR (Post1) and return visit after CR discharge (Post2). Patients walked in a 10-meter outdoor hallway without climate control for six minutes and the goal of the test was to cover the greatest distance. Hemodynamic responses to exercise using heart rate and blood pressure were measured immediately after the 6MWT and at five minutes of recovery.

\subsection{Statistical Analysis}

A factorial ANOVAs was used to compared between patients who agreed to participate in the study $(\mathrm{n}=52)$ and 
those who did not $(n=36)$ at the end of CR (Post1). Normality and homogeneity of variance were assessed using the Kolmogorov-Smirnov Test and Levene Test. Multiple 1 by 3 repeated-measures ANOVAs were used to determine significant changes with $\mathrm{CR}$ and at again 2.5 years after $\mathrm{CR}$. Bonferroni post hoc analysis was used when appropriate [28]. All data were analyzed using the Statistical Package for the Social Sciences (SPSS) version 21.0. Significance was accepted at $p<0.05$ level.

\section{Results}

The factorial analysis revealed no significant differences between those patients who agreed to participate $(n=52)$ and those who did not agree to participate $(n=36)$. Table 1 shows the baseline characteristics of patients measured at baseline and 30.7 months of follow-up after discharge from CR. On average, patients improved their 6MWT distance by $23.1 \%$ with CR $(443 \pm 95 \mathrm{~m}$ Pre to $545 \pm 87 \mathrm{~m}$ Post $1, p<$ 0.001 ), and this improvement was maintained at follow-up after discharge $(545 \pm 87 \mathrm{~m}$ Post 1 to $542 \pm 71 \mathrm{~m}$ Post2, $p>$ $0.05)$. Body weight increased $2.2 \%$ between CR discharge and follow-up $(75.8 \pm 12 \mathrm{~kg}$ Post1 to $77.5 \pm 13 \mathrm{~kg}$ Post2, $p=$ $0.002)$ and BMI increased $2.6 \%\left(26.9 \pm 3.4 \mathrm{~kg} / \mathrm{m}^{2}\right.$ Post 1 to
$27.6 \pm 3.6 \mathrm{~kg} / \mathrm{m}^{2}$ Post $\left.2, p=0.005\right)$. Waist circumference did not change at any of the evaluations. Resting HR decreased $7.0 \%$ between Post 1 and Post2 $(71 \pm 9.0$ to $66 \pm 11 \mathrm{bpm}$, respectively, $p=0.007$ ) and resting DBP was reduced by $5.6 \%$ with CR $(71 \pm 10 \mathrm{mmHg}$ Pre to $67 \pm 9.0 \mathrm{mmHg}$ Post 1 , $p=0.002)$ and was maintained after discharge $(67 \pm 9.0$ $\mathrm{mmHg}$ Post1 to $66 \pm 9.0 \mathrm{mmHg}$ Post $2, p>0.05)$. These data are presented in Table 2.

Table 1. Descriptive characteristics of cardiac patients at 2 to 3 years after discharge from cardiac rehabilitation.

\begin{tabular}{llll}
\hline Variable & Mean \pm SD & Minimum & Maximum \\
\hline Age $($ years $)$ & $59.1 \pm 14$ & 24 & 84 \\
Weight $(\mathrm{kg})$ & $77.5 \pm 13$ & 53.0 & 102.1 \\
Height $(\mathrm{cm})$ & $167.3 \pm 8.7$ & 146 & 188 \\
BMI $\left(\mathrm{kg} / \mathrm{m}^{2}\right)$ & $27.6 \pm 3.6$ & 20.2 & 35.5 \\
WC $(\mathrm{cm})$ & $96 \pm 9.5$ & 75.5 & 115.0 \\
Resting HR $(\mathrm{bpm})$ & $66 \pm 11$ & 44 & 93 \\
Resting SBP $(\mathrm{mmHg})$ & $108 \pm 15$ & 86 & 146 \\
Resting DBP $(\mathrm{mmHg})$ & $66 \pm 9.0$ & 50 & 80 \\
6MWT distance $(\mathrm{m})$ & $542.4 \pm 71.4$ & 390 & 660 \\
\hline
\end{tabular}

Abbreviations: $\mathrm{SD}=$ standard deviation, $\mathrm{BMI}=$ body mass index, $\mathrm{WC}=$ waist circumference, $\mathrm{HR}=$ heart rate, $\mathrm{bpm}=$ beats per minute, $\mathrm{SBP}=$ systolic blood pressure, DBP $=$ diastolic blood pressure, $6 \mathrm{MWT}=6$-minute walk test.

Table 2. Differences between Pre, Post1 and Post2 cardiac rehabilitation outcomes.

\begin{tabular}{|c|c|c|c|c|c|c|}
\hline \multirow{2}{*}{ Variable } & \multirow{2}{*}{ Pre-CR } & \multirow{2}{*}{ Post1-CR } & \multirow{2}{*}{ Post2-CR } & \multirow{2}{*}{$E S$} & \multicolumn{2}{|c|}{ 95\% Confidence Interval } \\
\hline & & & & & Lower Bound & Upper Bound \\
\hline Weight (kg) & $75.6 \pm 12^{\mathrm{a}}$ & $75.8 \pm 12^{\mathrm{a}}$ & $77.5 \pm 13^{b}$ & 0.48 & 0.54 & 2.90 \\
\hline $\operatorname{BMI}\left(\mathrm{kg} / \mathrm{m}^{2}\right)$ & $26.7 \pm 3.6^{\mathrm{a}}$ & $26.9 \pm 3.4^{\mathrm{a}}$ & $27.6 \pm 3.6^{\mathrm{b}}$ & 0.37 & 0.17 & 1.18 \\
\hline $\mathrm{WC}(\mathrm{cm})$ & $96 \pm 9.5^{\mathrm{a}}$ & $95 \pm 9.3^{\mathrm{a}}$ & $96 \pm 9.9^{\mathrm{a}}$ & 0.32 & -0.18 & 2.82 \\
\hline Resting HR (bpm) & $72 \pm 13.4^{\mathrm{a}}$ & $71 \pm 9.0^{\mathrm{a}}$ & $66 \pm 11^{\mathrm{b}}$ & -1.58 & -8.36 & -1.06 \\
\hline Resting SBP (mmHg) & $113 \pm 16.2^{\mathrm{a}}$ & $108 \pm 16.1^{\mathrm{a}}$ & $108 \pm 15^{\mathrm{a}}$ & 0.00 & -5.56 & 6.02 \\
\hline Resting DBP (mmHg) & $71 \pm 10^{\mathrm{a}}$ & $67 \pm 9.0^{\mathrm{b}}$ & $66 \pm 9.0^{\mathrm{b}}$ & -0.33 & -4.30 & 2.95 \\
\hline
\end{tabular}

Abbreviations: $\mathrm{CR}=$ cardiac rehabilitation, $\mathrm{BMI}=$ body mass index, $\mathrm{WC}=$ waist circumference, $\mathrm{HR}=$ heart rate, $\mathrm{bpm}=$ beats per minute, $\mathrm{SBP}=$ systolic blood pressure, $\mathrm{DBP}=$ diastolic blood pressure, $6 \mathrm{MWT}=6$-minute walk test. Means with different superscript letters are significantly different, ${ }^{\mathrm{a}-\mathrm{b}}=$ significantly different between pre-and-post $1 \mathrm{p}<0.05,{ }^{\mathrm{a}-\mathrm{b}}=$ significantly different between pre-and-post $2 \mathrm{p}<0.05$, ${ }^{\mathrm{a}-\mathrm{b}}=$ significantly different between post 1 -andpost $2 \mathrm{p}<0.05$

Patients exhibited better five minute heart rate recovery after the 6MWT with CR $(24 \pm 13 \mathrm{bpm}$ Pre vs $38 \pm 16 \mathrm{bpm}$ Post1, $p<0.001)$, which was maintained at follow-up (39 \pm 16 bpm Post1 vs $39 \pm 12$ bpm Post2, $p>0.05)$. Patients also had a greater SBP recovery with CR $(20 \pm 12 \mathrm{mmHg}$ Pre vs $29 \pm 16 \mathrm{mmHg}$ Post1, $p=0.004)$ and it was also maintained at follow-up after discharge $(29 \pm 16 \mathrm{mmHg}$ Post 1 vs $27 \pm 11$
$\mathrm{mmHg}$ Post2, $p>0.05)$. DBP recovery did not change in any of the three measurements. Patients showed a higher rate pressure product after CR $(13.066 \pm 3152 \mathrm{mmHg} * \mathrm{bpm}$ Pre vs $15.934 \pm 3962$ mmHg*bpm Post $1, p<0.001)$, which was maintained at follow-up $(15.934 \pm 3962 \mathrm{mmHg} *$ bpm Post 1 vs $14.933 \pm 3505 \mathrm{mmHg}{ }^{*}$ bpm Post2, $p>0.05$.) These data are presented in Table 3 .

Table 3. Hemodynamic responses to exercise after the 6MWT between Pre, Post 1 and Post 2 cardiac rehabilitation.

\begin{tabular}{|c|c|c|c|c|c|c|}
\hline \multirow{2}{*}{ Variable } & \multirow{2}{*}{ Pre-CR } & \multirow{2}{*}{ Post1-CR } & \multirow{2}{*}{ Post2-CR } & \multirow{2}{*}{ ES } & \multicolumn{2}{|c|}{ 95\% Confidence Interval } \\
\hline & & & & & Lower Bound & Upper Bound \\
\hline Final HR (bpm) & $100 \pm 20^{\mathrm{a}}$ & $115 \pm 22^{b}$ & $114 \pm 19^{b}$ & -0.22 & -7.31 & 4.24 \\
\hline Final SBP (mmHg) & $128 \pm 20^{\mathrm{a}}$ & $137 \pm 22^{b}$ & $134 \pm 19^{b}$ & -0.66 & -10.15 & 4.78 \\
\hline $\mathrm{RPP}(\mathrm{mmHg} * \mathrm{bpm})$ & $13066 \pm 3152^{\mathrm{a}}$ & $15934 \pm 3962^{b}$ & $14933 \pm 3505^{\mathrm{b}}$ & -16.38 & -2462.2 & 460.34 \\
\hline 5 min HR recovery (bpm) & $24 \pm 13^{\mathrm{a}}$ & $38 \pm 16^{\mathrm{b}}$ & $39 \pm 12^{b}$ & 0.27 & -7.50 & 1.50 \\
\hline 5 min SBP recovery $(\mathrm{mmHg})$ & $20 \pm 12^{\mathrm{a}}$ & $29 \pm 16^{b}$ & $27 \pm 11^{\mathrm{b}}$ & -0.54 & -8.40 & 5.05 \\
\hline
\end{tabular}

Abbreviations: $\mathrm{CR}=$ cardiac rehabilitation, $\mathrm{HR}=$ heart rate, $\mathrm{bpm}=$ beats per minute, $\mathrm{SBP}=$ systolic blood pressure, $\mathrm{DBP}=\mathrm{diastolic}$ blood pressure, $\mathrm{RPP}=$ rate pressure product. Means with different superscript letters are significantly different, ${ }^{\mathrm{a}-\mathrm{b}}=$ significantly different between pre-and-post $1 \mathrm{p}<0.05$. 


\section{Discussion}

The purpose of the present study was to examine the maintenance of functional capacity and hemodynamic responses to exercise in cardiac patients two to three years after discharge from a traditional 12-wk CR program. Patients maintained their functional capacity and hemodynamic responses to exercise two and a half years after discharge from CR despite they gained body weight. Findings from the present study are consistent with previous reports in terms of improvements in functional capacity and hemodynamic responses to exercise after CR [4-6, 16, 19, 29]. However, the results regarding maintenance in functional capacity are inconsistent with those reported in previous studies [6, 22, 29]. Gupta and colleagues [6] reported that cardiac patients exhibited $7.8 \%$ decrease in the distance covered during the 6MWT at one-year follow-up after discharge from CR [6]. In the present study, an increase of $23.1 \%$ in functional capacity measured by the $6 \mathrm{MWT}$ was observed, which is equivalent to an increase of $0.6 \mathrm{mph}$ after CR. Kavanagh et al. [15] reported that every 1-mph increase in walking speed was associated with a $20 \%$ decrease in cardiovascular mortality in $\mathrm{CAD}$ patients. In addition, the present study reported that the distance of the 6MWT was maintained at two years or more after exiting the program, which is not consistent with previous studies [6, 29]. In contrast, increases in functional capacity of $24.3 \%$ have been reported in patients who had a medical follow-up every 6 months and $18.3 \%$ in those who had no follow-up [24]. However, Gupta et al. [6] found a $19.3 \%$ decrease in functional capacity at one year after discharge from CR, with or without medical follow-up. Patients who received medical follow-up showed less loss of functional capacity [6]. It is possible that maintenance of functional capacity after the CR program was due to adherence to exercise or telephone follow-up that was given to the patients in some studies [6, 24]. In the present study, no medical or telephone follow-up were done. However, $35 \%$ of the cardiac patients in the study reported that continue exercising 3 times per week and $21 \%$ reported that maintained their exercise more than 3 times per week. Moreover, 19\% of them indicated that they exercised once or twice per week, the rest of the patients reported not been physically active.

Regarding body weight and BMI, the present study found that body weight increased by $2.2 \%$ two and a half years after discharge from $\mathrm{CR}$, equivalent to 1.7 kilograms, and $\mathrm{BMI}$ increased by $2.6 \%$. These results are similar to previous studies [21, 22]. In patients with CVD who had been discharged from the CR program for over 6 months, body weight and BMI increased by $2 \%$ [21]. In another study, 34 patients with CVD also reported that body weight increases 2 kilograms after 12 months of follow-up [26]. In both studies, the authors indicated that the increases in body weight might have been due to poor eating habits and lack of physical activity [21, 26]. However, other studies have reported decreases in body weight and BMI between $2 \%$ and $6 \%$ after
12,24 and 36 months after discharge from a CR program [6, 24, 30].

With respect to hemodynamic responses at rest, the present study found a 5.6\% decrease in resting DBP after CR which is consistent with previous studies that reported reductions of $2.9 \%$ and $9 \%$ after CR, respectively $[5,16]$. Resting SBP did not improve after $\mathrm{CR}$, which is consistent with another study of cardiac patients [22]. However, the results obtained here are different from previous investigations that showed decreases in SBP between $3.5 \%$ and $11 \%$ after completing CR $[5,16,26]$. Likewise, in this study a 5.6\% DBP decrease was observed after $\mathrm{CR}$ and was maintained for two and a half years after discharge, similar to the findings of another study that reported a $15 \%$ reduction two years after discharge from CR [22]. However, other studies have reported adverse outcomes, showing increases in SBP and DBP at rest at one or one and a half years after discharge from a CR program $[17,26]$. An exercise-based CR program has been shown to reduce blood pressure may be due to increases in the endothelium-dependent vasodilation of the blood vessels, possibly due to an increase in nitric oxide production [31].

The data for resting heart rate in the present study did not decreased after $\mathrm{CR}$, similar to the findings of previous studies $[5,22]$, although unlike another study which showed decreases of $12 \%$ after CR [16]. However, resting heart rate in the present study declined by $8 \%$ at two and a half years after discharge, similar to findings from another study that reported decreases of $15 \%$ two years after discharge from CR [22]. HR decreased after discharge probably because exercise training increases vagal tone activity and attenuates sympathetic hyperactivity, that may improve autonomic markers of neuronal regulation and cardiac variability [32]. With respect to hemodynamic responses after the 6MWT, in the present study heart rate and SBP at five minutes of recovery after $\mathrm{CR}$, were 38 beats per minute and $29 \mathrm{mmHg}$ lower than the initial assessment and these results are similar to previous studies with cardiac and heart failure patients [5, 33]. It has been reported that heart rate recovery after a 6MWT is a good predictor of cardiac events in heart failure patients. In addition, patients with low heart rate recovery after the 6MWT have a higher risk of cardiovascular mortality [33]. Importantly, exercise training causes cardiovascular adaptations such as greater stroke volume and lower heart rate maybe due to an increased parasympathetic activity that may reduce heart rate recovery [34]. Similarly, improvements in systolic blood pressure recovery after training may be due to less total peripheral resistance in the blood vessels mediated by nitric oxide production from the endothelium causing vasodilation [35].

\section{Limitations}

This is a small observational study from a single cardiac rehabilitation program in a university-based setting. The patients were not followed-up after discharge from the phase II cardiac rehabilitation program, were called after discharge, 
and ask them to participate in the study. This study was limited by the lack of a control group. A physical activity questionnaire was not administered during the follow-up period and were reliance on self-report measures of the physical activity. Patients were not asked to change their medication after discharge.

\section{Conclusions}

Patients with cardiovascular disease that underwent a traditional twelve-week exercise-based cardiac rehabilitation program, maintained their functional capacity and hemodynamic responses to exercise two and a half years after discharge from CR. However, body weight was not maintained after exiting the CR program.

\section{Conflict of Interest}

All the authors do not have any possible conflicts of interest.

\section{References}

[1] Ministerio de Salud: Memoria Institucional 2010-2014. Ministerio de Salud 2014:1-194.

[2] World Health Organization: World Health Statistics 2012. WHO Library Cataloguing-in-Publication Data 2012:34-35.

[3] Mozaffarian D, Benjamin MJ, Go AS, Arnett D, K., Blaha MJ, Cushman M, Das SR, Ferranti S, JDesprés JP, Fullerton HJ: Heart Disease and Stroke Statistics-2016 Update. A Report From the American Heart Association. Circulation 2016, 133:e38-e360.

[4] Araya-Ramírez F, Briggs KK, Bishop SR, Miller CE, Moncada-Jiménez J, Grandjean PW: Who is likely to benefit from phase II cardiac rehabilitation?. J Cardiopulm Rehabil Prev 2010, 30 (2):93-100.

[5] Araya-Ramírez F, Ureña-Bonilla $P$, Blanco-Romero L, Grandjean PW: Efecto de un programa de ejercicios en la capacidad funcional y respuesta hemodinámica de pacientes con enfermedad cardiovascular. Rev Costarricense de Cardiología 2014, 16 (2):5-11.

[6] Gupta R, Sanderson BK, Bittner V: Outcomes at one-year follow-up of women and men with coronary artery disease discharged from cardiac rehabilitation: what benefits are maintained? J Cardiopulm Rehabil Prev 2007, 27 (1):11-18.

[7] Lavie CJ, Milani RV: Effects of cardiac rehabilitation programs on exercise capacity, coronary risk factors, behavioral characteristics, and quality of life in a large elderly cohort. American Journal of Cardiology 1995, 76 (3):177-179.

[8] Thompson PD, Buchner D, Piña IL, Balady GJ, Williams MA, Marcus B, Berra K, Blair SN, Costa F, Franklin BA et al: Exercise and Physical Activity in the Prevention and Treatment of Atherosclerotic Cardiovascular Disease Arteriosclerosis, Thrombosis, and Vascular Biology 2003, 23 (1):42-49.
[9] Williams MA, Ades PA, Hamm LF, Keteyian SJ, LaFontaine TP, Roitman JL, Squires RW: Clinical evidence for a health benefit from cardiac rehabilitation: an update. Am Heart $J$ 2006, 152 (5):835-841.

[10] Franklin BA, Lavie CJ, Squires RW: Exercise-Based Cardiac Rehabilitation and Improvements in Cardiorespiratory Fitness: Implications Regarding Patient Benefit. Mayo Clin Proc 2013, 88 (5):431-437.

[11] Listerman J, Bittner V, Sanderson BK, Brown TM: Cardiac rehabilitation outcomes: impact of comorbidities and age. $J$ Cardiopulm Rehabil Prev 2011, 31 (6):342-348.

[12] Ades PA, Maloney A, Savage P, Carhart R: Determinants of physical functioning in coronary patients: response to cardiac rehabilitation. Archives of Internal Medicine 1999, 159 (19):2357-2360.

[13] Lear SA, Spinelli JJ, Linden W, Brozic A, Kiess M, Frohlich JJ, Ignaszewski A: The Extensive Lifestyle Management Intervention (ELMI) after cardiac rehabilitation: a 4-year randomized controlled trial.. American Heart Journal 2006, 152 (2):333-339.

[14] Williams MA, Haskell WL, Ades PA, Amsterdam EA, Bittner v, Franklin BA, Gulanick M, Laing ST, Stewart KJ: Resistance Exercise in Individuals With and Without Cardiovascular Disease: 2007 Update. A Scientific Statement From the American Heart Association Council on Clinical Cardiology and Council on Nutrition, Physical Activity, and Metabolism. Circulation 2007, 16:572-584.

[15] Kavanagh T, Hamm LF, Beyene J, Mertens DJ, Kennedy J, Campbell R, Fallah S, Shephard RJ: Usefulness of Improvement in Walking Distance Versus Peak Oxygen Uptake in Predicting Prognosis After Myocardial Infarction and/or Coronary Artery Bypass Grafting in Men. Am J Cardiol 2008, 101:1423-1427.

[16] Ghashghaei FE, Sadeghi M, Marandi SM, Ghashghaei SE: Exercise-based cardiac rehabilitation improves hemodynamic responses after coronary artery bypass graft surgery. ARYA Atherosclerosis 2012, 7:151-156.

[17] Hansen D, Dendale P, Raskin A, Schoonis A, Berger J, Vlassak I, Meeusen R: Long-term effect of rehabilitation in coronary artery disease patients: randomized clinical trial of the impact of exercise volume.. Clinical Rehabilitation 2010, $24(4): 319-327$.

[18] Reid L, Morrin A, Pipe A, Dafoe W, Lyall H, Wielgosz A, McDonald P, Plotnikoff R, Higginson L, Oldridge N et al: Determinants of physical activity after hospitalization for coronary artery disease: the Tracking Exercise after Cardiac Hospitalization (TEACH) Study.. European Journal of Cardiovascular Prevention and Rehabilitation 2006, 13 (4):529-537.

[19] Volaklis K, Douda T, Kokkinos F, Tokmakidis S: Physiological alterations to detraining following prolonged combined strength and aerobic training in cardiac patients. European Journal of Cardiovascular Prevention and Rehabilitation 2006, 13 (3):375-380.

[20] Tokmakidis S, Volaklis K: Training and detraining effects of a combined strength and aerobic training program on blood lipids in patients with coronary artery disease. J Cardiopulm Rehabil 2003, 23:193-200. 
[21] Mandic S, Hodge C, Stevens E, Walker R, Nye E, Body D, Barclay L, Williams M: Effects of Community-Based Cardiac Rehabilitation on Body Composition and Physical Function in Individuals with Stable Coronary Artery Disease: 1.6-Year Follow up. BioMed Research International 2013, 1:1-7.

[22] Bosch C, Myers J, Habersaat A, Ibarraza H, Kottman W, Dubach P: Maintenance of Exercise Capacity and Physical Activity Patterns 2 Years After Cardiac Rehabilitation.. Journal of Cardiopulmonary Rehabilitation and Prevention 2005, 25 (1):14-21.

[23] Brubaker PH, Warner JGJ, Rejeski WJ, Edwards DG, Matrazzo BA, Ribisl PM, Miller HSJ, Herrington DM Comparison of standard- and extended-length participation in cardiac rehabilitation on body composition, functional capacity, and blood lipids. Am J Cardiol 1996, 78 (7):769-773.

[24] Giannuzzi P, Temporelli P, Marchioli R, Pietro A, Balestroni G, Ceci V, Chieffo C, Gattone M, Griffo R, Schweiger C et al: Global secondary prevention strategies to limit event recurrence after myocardial infarction: results of the GOSPEL study, a multicenter, randomized controlled trial from the Italian Cardiac Rehabilitation Network.. Archives of Internal Medicine 2008, 168 (20):2194-2204.

[25] Rogers M, Yamamoto C, Hagberg J, Holloszy J, Ehsani A: The effect of 7 years of intense exercise training on patients with coronary artery disease. Journal of the American College of Cardiology 1987, 10 (2):321-326.

[26] Willich S, Müller J, Kulig M, Binting S, Gohlke H, Hahnmann H, Bestehorn K, Krobot K, Völler H: Cardiac risk factors, medication, and recurrent clinical events after acute coronary disease. A prospective cohort study. European Heart Journal 2001, 22 (4):307-313.

[27] Steele B: Timed walking tests of exercise capacity in chronic cardiopulmonary illness J Cardiopulm Rehabil 1996, 16:2533.
[28] Kim HY: Statistical notes for clinical researchers: post-hoc multiple comparisons. Restor Dent Endod 2015, 40 (2):172176.

[29] Oerkild B, Frederiksen M, Hansen F, Simonsen L, Skovgaard L, Prescott E: Home-based cardiac rehabilitation is as effective as centre-based cardiac rehabilitation among elderly with coronary heart disease: results from a randomized clinical trial. Age and Ageing 2011, 40 (1):78-85.

[30] Bock B, Carmona R, Esler J, Tikemeir P: Program Participation and Physical Activity Maintenance after Cardiac Rehabilitation. Behavior Modification. 27 2003, 1.

[31] Walther C, Gielen S, Hambrecht R: The effect of exercise training on endothelial function in cardiovascular disease in humans. Exerc Sport Sci Rev 2004, 32:129 - 134.

[32] Curtis B, O'Keefe J: Autonomic tone as a cardiovascular risk factor: the dangers of chronic fight or flight. Mayo Clin Proc $2002,77: 45-54$

[33] Cahalin LP, Arena R, Labate V, Bandera F, Lavie CJ, Guazzi M: Heart rate recovery after the 6 min walk test rather than distance ambulated is a powerful prognostic indicator in heart failure with reduced and preserved ejection fraction: a comparison with cardiopulmonary exercise testing. European Journal of Heart Failure 2013, 15:519-527.

[34] Mujika I, Badilla S: Cardiorespiratory and metabolic characteristics of detraining in humans. Med Sci Sports Exerc 2001, 33 (3):413-421.

[35] Hambrecht R, Adams V, Erbs S, Linke A, Kränkel N, Shu Y, Baither Y, Gielen S, Thiele H, Gummert JF et al: Regular physical activity improves endothelial function in patients with coronary artery disease by increasing phosphorylation of endothelial nitric oxide synthase. Circulation 2003, 107 (25):3152-3158. 